\title{
Metallurgical Phase Transformation and Behavior of Steels Under Impact Loading
}

\begin{abstract}
M. ZEROUKI, M. OULD OUALI, and L. BENABOU
This study deals with the mechanical behavior of the austenitic stainless steel, AISI 304, under quasi-static and impact loadings. In particular, the evolution of the transformation-induced plasticity (TRIP) is investigated. Several compression tests have been performed at various strain rates under both static and impact conditions (crash tests). In order to show the influence of the strain rate on the phase transformation, the microstructures of as-received and deformed specimens have been observed with a scanning electron microscope. Then, the newly formed ferromagnetic martensitic phase is analyzed with the help of the vibrating sample magnetic (VSM) method and by X-ray diffraction (XRD). The results obtained from the mechanical testing indicate that the TRIP effect is actually occurring since a significant change of the curve slope is visible during the hardening regime in the stress-strain curve. The VSM and XRD techniques, on the other hand, show that the proportion of the martensitic phase is reduced when the strain rate is increased. The quantity of martensite formed is greater when quasi-static loadings are applied to the material.
\end{abstract}

https://doi.org/10.1007/s11661-019-05527-z

(C) The Minerals, Metals \& Materials Society and ASM International 2019

\section{INTRODUCTION}

DUE to its good mechanical, chemical, and physical properties, stainless steel is widely employed in many sectors of industry. Several classes of this material have been developed for various applications and are used in daily life. In the present study, we deal with a certain type of stainless steel which is characterized by the transformation-induced plasticity (TRIP) effect. ${ }^{[1]}$ This stainless steel is usually employed in safety-critical parts like hinges, as well as in stiffeners of complex shapes. Galán et al. ${ }^{[2]}$ assessed that TRIP steel are good choice for crash performance due to their excellent energy absorption ability, high strain-hardening rates, high mechanical strength combined to a strong bake hardening effect. So, these steels are used in structural and reinforcement parts of complex shape, cross members, longitudinal beams, sills, and bumper reinforcements in automotive. $^{[3]}$

The TRIP phenomenon corresponds to the transformation of austenite to martensite under the effect of mechanical loading, heating, or both. Zackay et al. ${ }^{[4]}$

M. ZEROUKI and M. OULD OUALI are with the Laboratoire Élaboration et Caractérisation des Matériaux et Modélisation (LEC2M), Université Mouloud MAMMERI de Tizi-Ouzou, Tizi Ouzou, Algeria. L. BENABOU is with the LISV, Université de Versailles Saint-Quentin-en-Yvelines, Paris Saclay, France. Contact email: lahouari.benabou@uvsq.fr

Manuscript submitted June 4, 2019.

Article published online November 11, 2019 attribute the high strain-hardening rate of TRIP steels to the deformation of the hard second-phase martensite dispersed in the soft ferrite matrix as well as to the transformation of retained austenite to martensite which increases the hardening rate at higher strain levels during deformation.

The ductile austenitic matrix, containing lath martensite after the phase transformation, has not only a greater elongation at rupture but also a greater strength. The plastic strain originating from the martensitic transformation is referred to as transformation plasticity. ${ }^{[5-7]}$ This form of plasticity contributes remarkably to the mechanical properties of this class of stainless steels by improving their ductility, strength, strain-hardening capacity, and delays the occurrence of necking. ${ }^{[8-10]}$ Sached $v^{[11]}$ studied the effect of residual austenite on the tensile behavior of a dual phase steel at temperatures between $-50{ }^{\circ} \mathrm{C}$ and $187^{\circ} \mathrm{C}$, suggesting that the ductility of dual phase steels can be further improved by optimizing the stability of the retained austenite. Authors ${ }^{[12-14]}$ concluded that the rate of transformation of retained austenite and thus, its mechanical stability are the key factors that influence the work hardening behavior of TRIP-assisted steels.

Olson and co-workers ${ }^{[15-19]}$ studied the mechanism of the strain-induced nucleation of martensitic transformations and its effect on the overall behavior of material. They proposed a numerical model for transformation plasticity accompanying strain-induced martensitic transformations in metastable austenitic steels. 
The martensitic transformation can lead to two types of microstructure: martensite is either in the form of lath martensite with high dislocation density ${ }^{[4,20]}$ or it has a needle-like microstructure.

Many studies ${ }^{[21-23]}$ have shown that the improvement of the material properties of the TRIP steels is related to two microscale mechanisms, the Magee mechanism $^{[24-26]}$ and the Greenwood-Johnson mechanism, ${ }^{[27-29]}$ respectively. It is now generally accepted that the Magee mechanism corresponds to the formation in the austenite of the martensitic variants due to the local stress state, while the Greenwood-Johnson mechanism corresponds to the microscale plasticity arising in the austenite from the expansion of the newly formed phase. Among these studies, the investigations in References 30-32 have concluded that, during cooling under loading, a stress variation induces a variation of transformation plastic strain of opposite sign. The influence of the strain rate on the kinetics of the martensitic transformation for small levels of deformation $(\varepsilon=0.2)$ was investigated in Reference 9; it was established that the proportion of formed martensite increases when the strain rate is increased. For larger deformations, the trend is reversed; in that case, the proportion of formed martensite is higher for lower strain rates. This phenomenon can be explained by the fact that the latent heat of martensite formation and the heat related to the plastic process become extremely high in the case of relatively fast strain rates to allow the phase transformation to continue. Talonen et al. ${ }^{[33,34]}$ have shown that, for the unstable austenitic steel AISI 304 , a strain level of 30 pct with a strain rate of $10 \mathrm{~s}^{-1}$ results in a temperature increase of $60^{\circ} \mathrm{C}$. Lebedev ${ }^{[35]}$ has performed uniaxial tensile tests, torsion tests and compression tests on the austenitic steel AISI 304, concluding that the TRIP effect occurs earlier under uniaxial tension than under torsion or under compression. This is explained by the fact that, under tension, the number of martensitic nucleation sites is larger. Miller and McDowell ${ }^{[36]}$ have measured for the stainless steel $304 \mathrm{~L}$ a greater proportion of formed martensite under compression than under torsion. The experiments carried out by Iwamoto et al. ${ }^{[37]}$ on a stainless steel indicate that, in the case of small strains, the martensitic transformation in uniaxial compression occurs at an

Table I. Chemical Composition of the Stainless Steel AISI 304 Given in Pet Mass of Elements

\begin{tabular}{lccccc}
\hline $\mathrm{C}$ & $\mathrm{Si}$ & $\mathrm{Mn}$ & $\mathrm{Cr}$ & $\mathrm{Mo}$ & $\mathrm{Ni}$ \\
\hline 0.024 & 0.35 & 1.31 & 18.40 & 0.23 & 8.05 \\
\hline
\end{tabular}

earlier stage than in uniaxial tension. Krüger et al. ${ }^{[38,39]}$ carried out dynamic compression tests on TRIP steels to determine the dependence of their transformation on the loading rate. The tests show that the proportion of martensite decreases when the strain rate is increased. However, yield strength is increased in the dynamic case. The tests performed by Yoo et al. ${ }^{[40,41]}$ with stainless steel AISI 304 under tension at low strain rates demonstrate that the strain rate has an influence on the global behavior of steel, in particular at low temperatures.

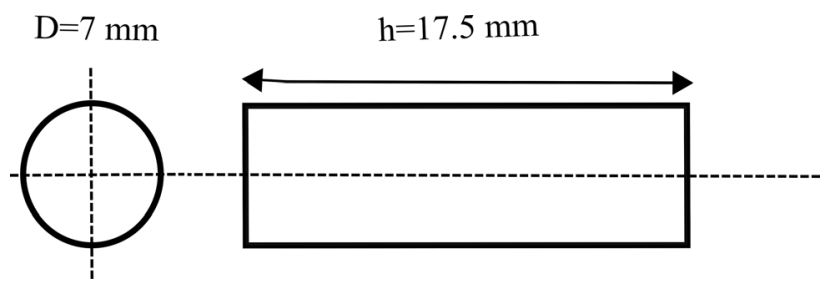

Fig. 1-Geometry and dimensions of the specimens used for the quasi-static and dynamic tests.

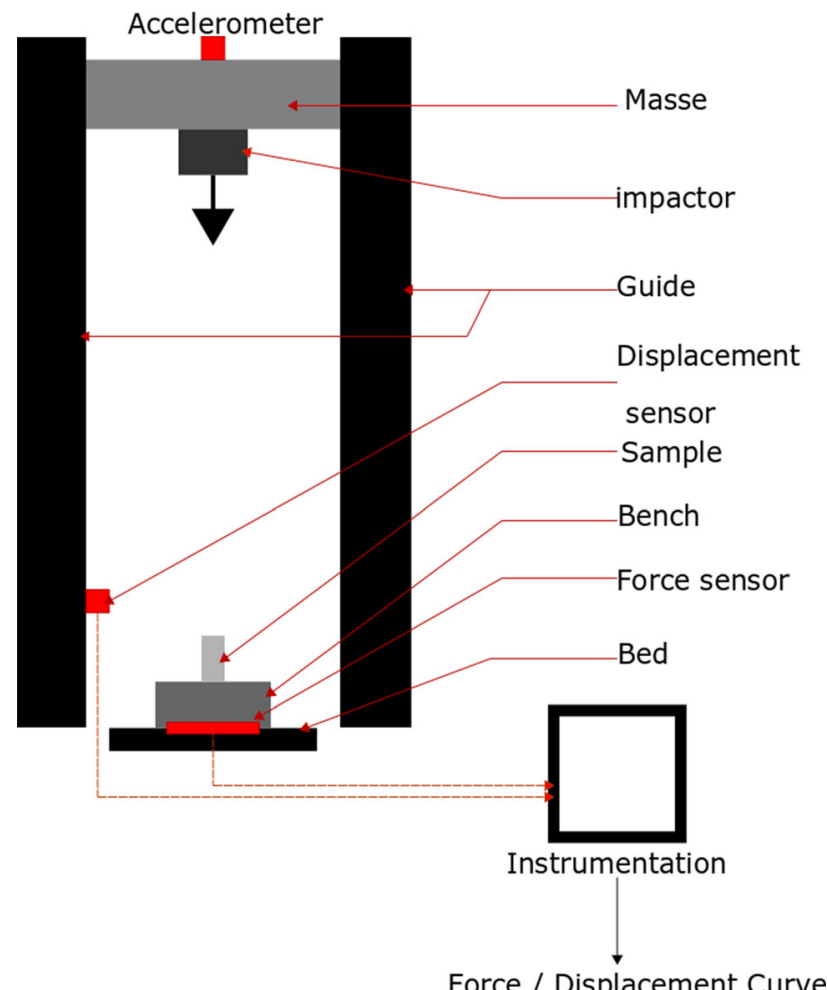

Force / Displacement Curve

Fig. 2-Schematic of the falling weight impact tester.

Table II. Mechanical Properties of the Stainless Steel AISI 304

\begin{tabular}{lccccc}
\hline$E(\mathrm{MPa})$ & $v$ & $\mathrm{Re}(\mathrm{MPa})$ & $\mathrm{Rm}(\mathrm{MPa})$ & Elongation $(\mathrm{Pct})$ & Hardness $(\mathrm{HB})$ \\
\hline 195,000 & 0.33 & 500 & 783 & 48 & 224.7 \\
\hline
\end{tabular}


This present work is dedicated to the investigation of the TRIP effect in the stainless steel AISI 304. Both the mechanical behavior of the material and the evolution of its microstructure before and after loading are analyzed. The main objective is to get a deeper understanding of the TRIP mechanism under dynamic loading (impact test). Quasi-static loading is also considered in the study in order to reproduce the well-established characteristics associated with the TRIP mechanism and assess the validity of our experimental setup. In Section II, the various experimental techniques used for the microstructural observations and the methods employed for testing and evaluating the material properties are presented. Among other techniques, the vibrating sample magnetic (VSM) method, used to quantify the amount of the formed martensitic phase, is described. In Section III, the results of the various loading tests under static and dynamic conditions are discussed. The different data collected from all the performed measurements are analyzed in relationship with the martensitic transformation in the material. Finally, in Section IV, conclusive remarks are made on the experimental work carried out in this study and perspectives are proposed for completing this work with, in particular, a modeling approach of the TRIP mechanism under dynamic loading.

\section{EXPERIMENTAL METHODS}

The material under investigation is an austenitic stainless steel AISI 304. ${ }^{[4]}$ The specimens used for the tests are in the form of rods with a cross-sectional diameter $D=7 \mathrm{~mm}$. The chemical composition is given in Table I. This steel grade is unstable at ambient temperature and promotes the martensitic transformation under the effect of plastic deformation due to the small amount of nickel (8.05 pct). Table II summarizes the mechanical properties of the material.

The quasi-static compression tests are done with a universal tensile machine INSTRON at 3 strain rates: $10^{-4}, 10^{-3}$, and $10^{-2} \mathrm{~s}^{-1}$, respectively. The geometry and

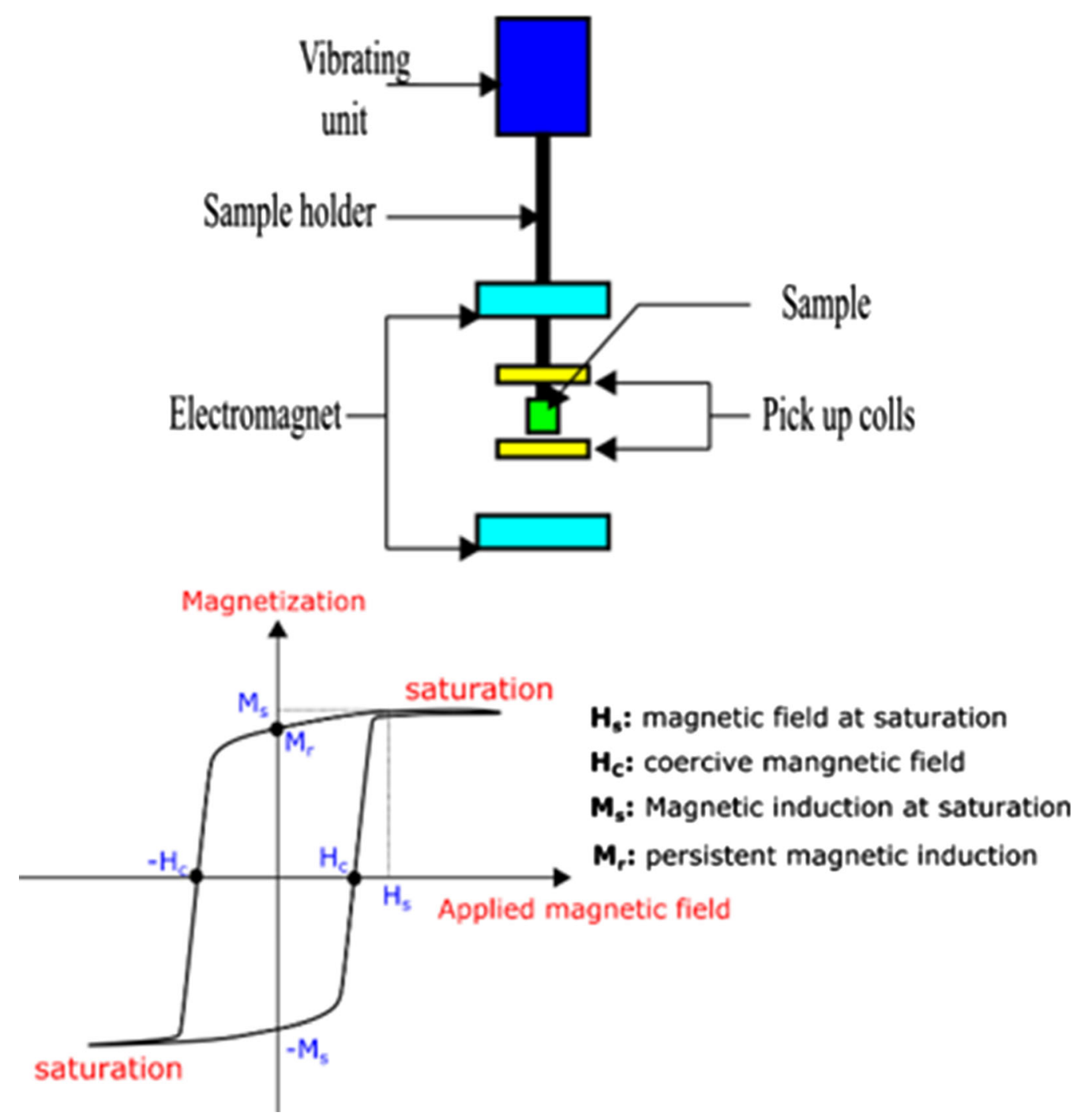

Fig. 3- Schematic of the VSM apparatus and typical curve obtained with this method. 
dimensions of the specimens are represented in Figure 1. The same dimensions are used for the impact tests with falling weight at 3 different speeds: 5,6 , and $8 \mathrm{~m} \mathrm{~s}^{-1}$, respectively. The falling weight impact tester is schematized in Figure 2.

The Brinell hardness tests are carried out on a "Weinheim-Birkenau" device on polished samples before and after deformation with a load of $60 \mathrm{~N}$ and a holding time of 10 seconds.

The micro-hardness tests are carried out on a "Zwich Roell ZHV" type apparatus on polished samples which were subjected to an electro-chemical attack to reveal the austenitic and martensitic phases. The indenter is of Brinell type. A charge of $588 \mathrm{~N}$ is imposed with a holding time of 5 seconds on samples before and after deformation.

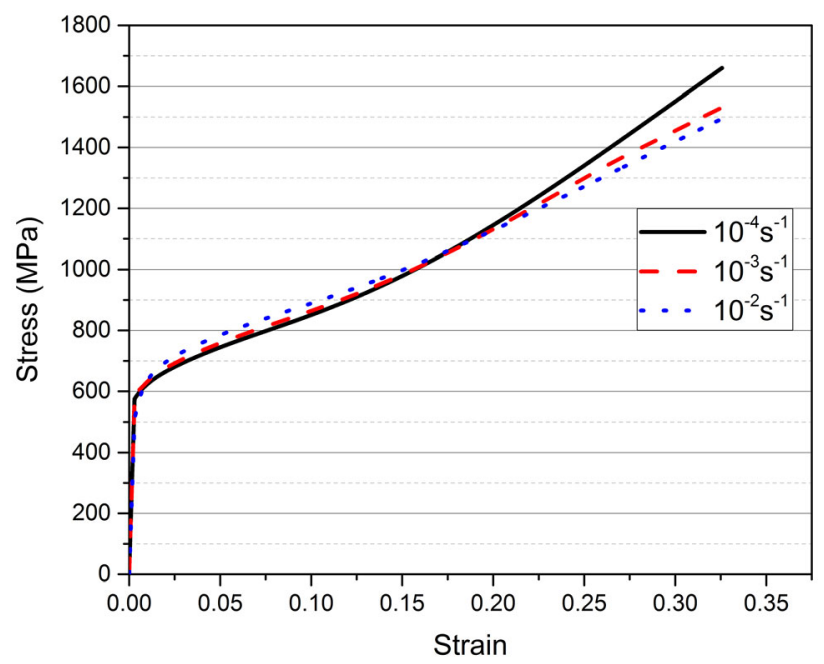

Fig. 4-Stress-strain curves under quasi-static compression for different strain rates.

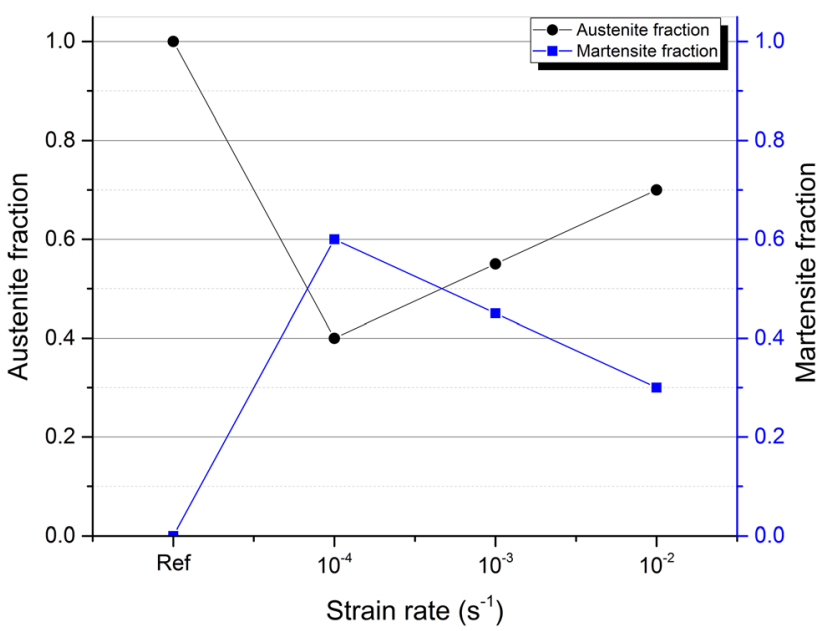

Fig. 5-Amounts of martensite and residual austenite for different compression rates under quasi-static loading.
X-ray diffraction was done to identify the nature of different phases. For this, a Panalytical X'PERT Pro diffractometer with $\mathrm{CuK} \alpha$ radiation using $40 \mathrm{kV}$ operating voltage and $40 \mathrm{~mA}$ current was used to study our samples. The diffracting angle $2 \theta$ was scanned from 0 to $140 \mathrm{deg}$ with step size of $0.016 \mathrm{deg}$ and measuring time of 8 seconds per step.

The SEM analyses are carried out on a Philips XL30 apparatus with tungsten filament in BSE (back scattered electron) mode to reveal the chemical contrast on polished samples.

The vibrating sample magnetic method is used to analyze the formation of the martensitic phase. The principle of the VSM method is to measure the induced flux in the resistive detection module based on the periodical shift of the sample with magnetization $M$ (Figure 3). The sample is placed at the center of the detection module and is subjected to vibrational motion with frequency $f_{0}$ and amplitude $A$. The detection module is made of 4 copper coils connected in series opposition and paired up in a two-coil compensation configuration to obtain both axial and radial compensations. The specimen of dimension $3 \times 3 \mathrm{~mm}$ is inserted into the VSM equipment and subjected to maximum inductor magnetic field of $2 \mathrm{~T}$, aiming to get magnetization of saturation for each sample before and after deformation.

\section{RESULTS AND DISCUSSION}

\section{A. Quasi-Static Testing}

The stress-strain curves obtained under quasi-static compression for different strain rates are plotted in Figure 4. It can be noted that the response of the material is rather weakly affected by the deformation rate when the overall strain remains under 17 pct. When this threshold is exceeded, the effect of the deformation rate is quite visible with increased strain-hardening when the strain rate is low. This suggests that the formation of martensite is inversely proportional to the deformation rate. ${ }^{[43-45]}$ Figure 5 shows the amounts of martensite and austenite phases after different loading speeds. The

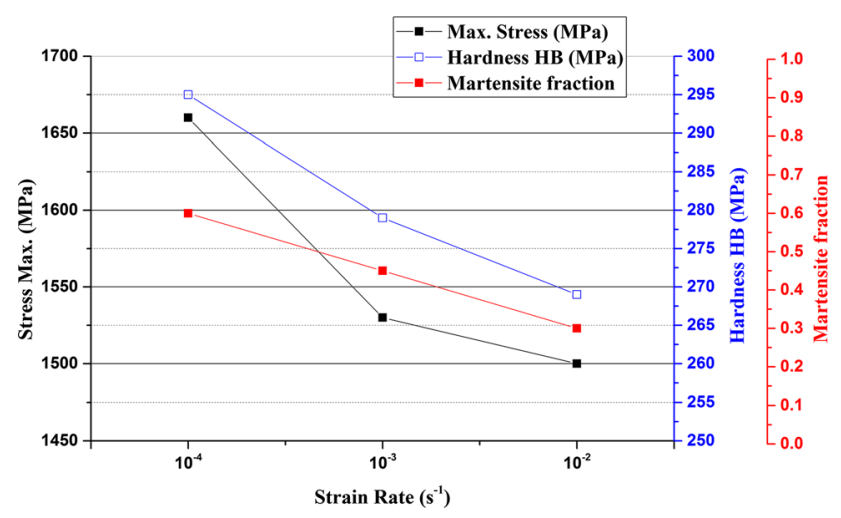

Fig. 6-Evolutions of the maximum stress and the hardness as functions of the compression rate, correlated with martensite fraction. 


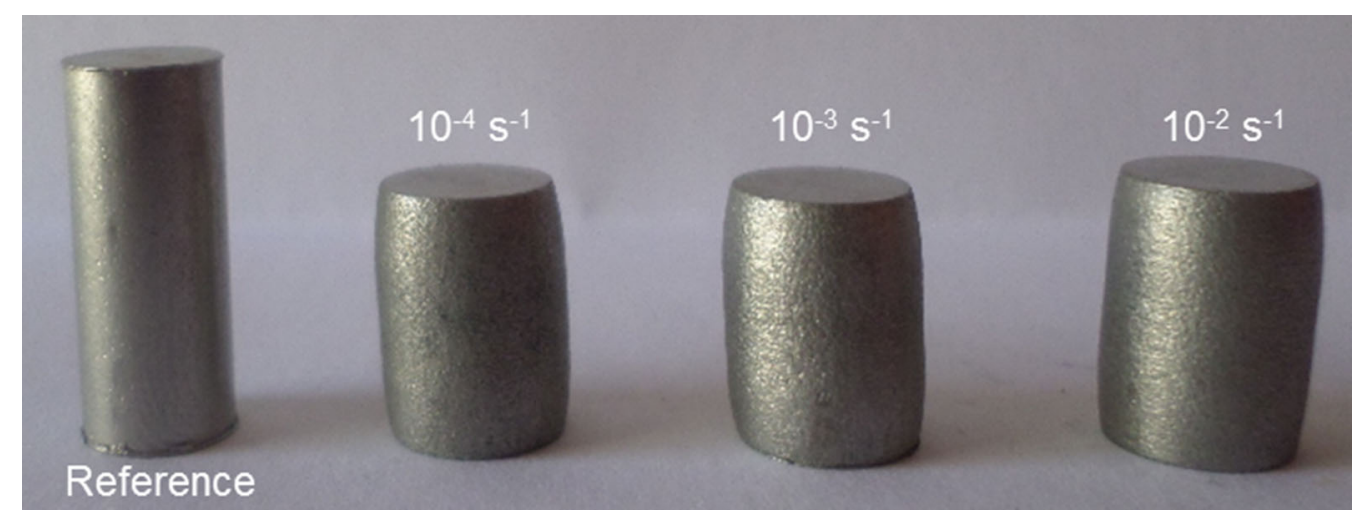

Fig. 7-Deformed shapes of specimens before and after compression loading.

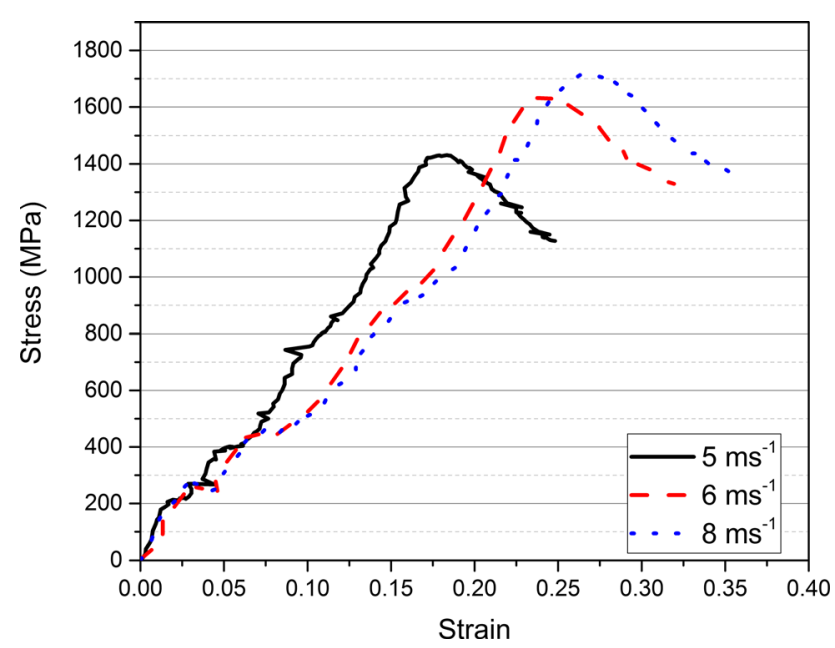

Fig. 8- Stress-strain curves during impact for three different speeds.

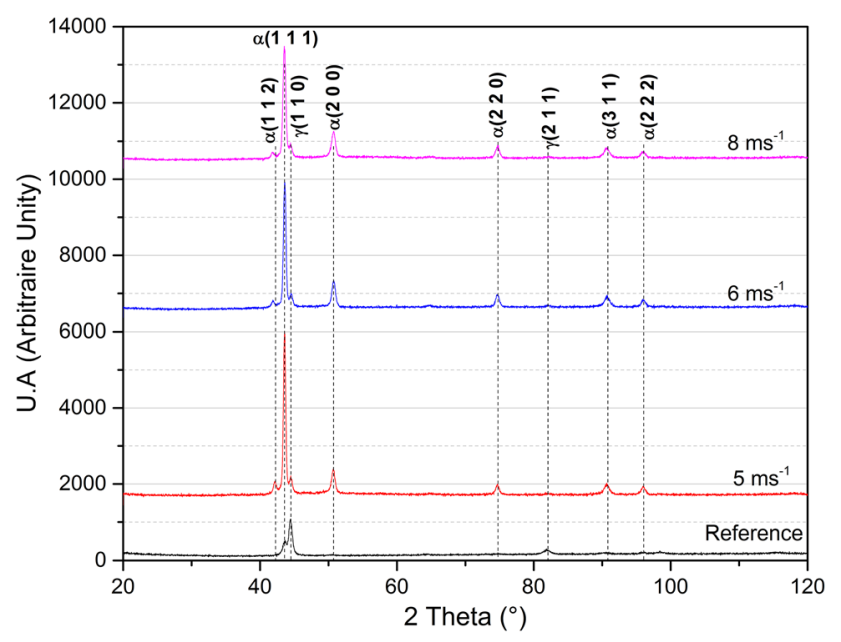

Fig. 10-X-ray diffraction diagrams for the specimens impacted at 5, 6 , and $8 \mathrm{~m} \mathrm{~s}^{-1}$.

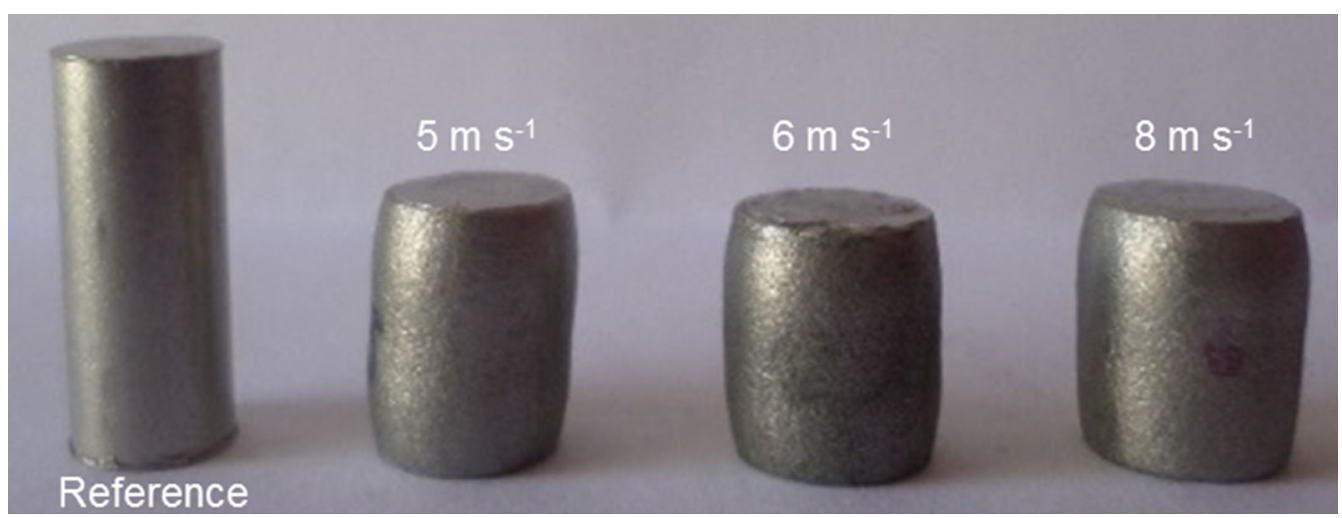

Fig. 9- Specimens before and after being impacted at different speeds by the falling weight. 


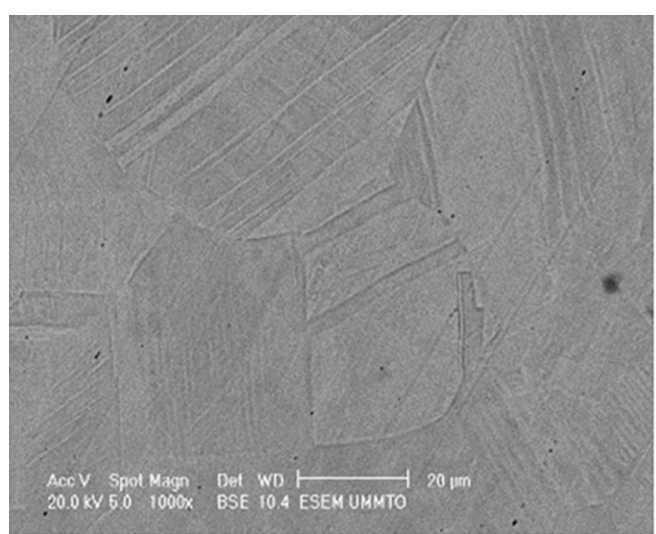

before deformation

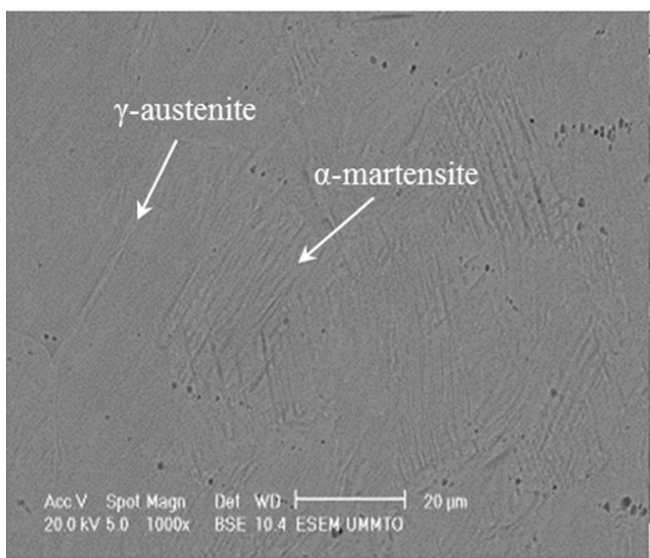

$6 \mathrm{~m} \mathrm{~s}^{-1}$

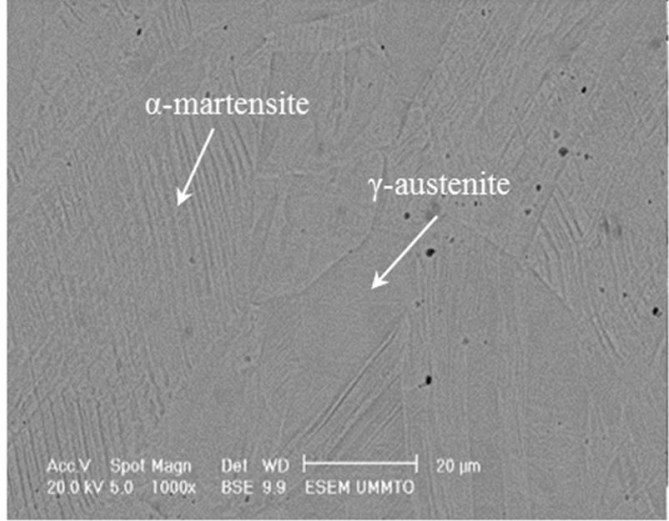

$5 \mathrm{~m} \mathrm{~s}^{-1}$

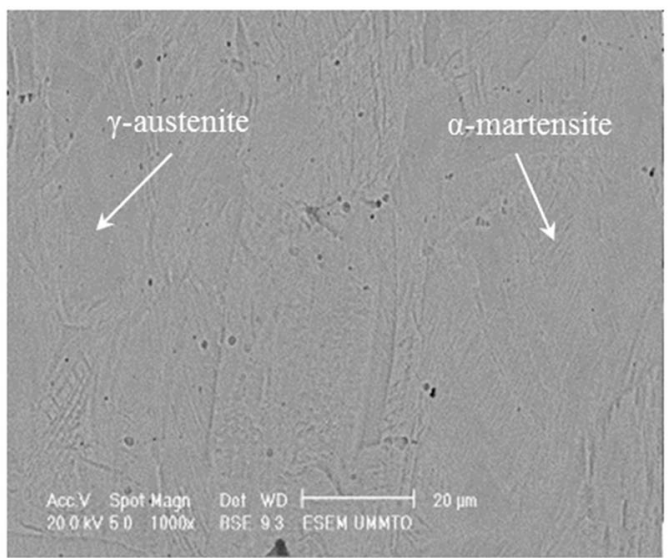

$8 \mathrm{~m} \mathrm{~s}^{-1}$

Fig. 11-SEM views of specimen cross-sections before and after impact at the three different speeds.

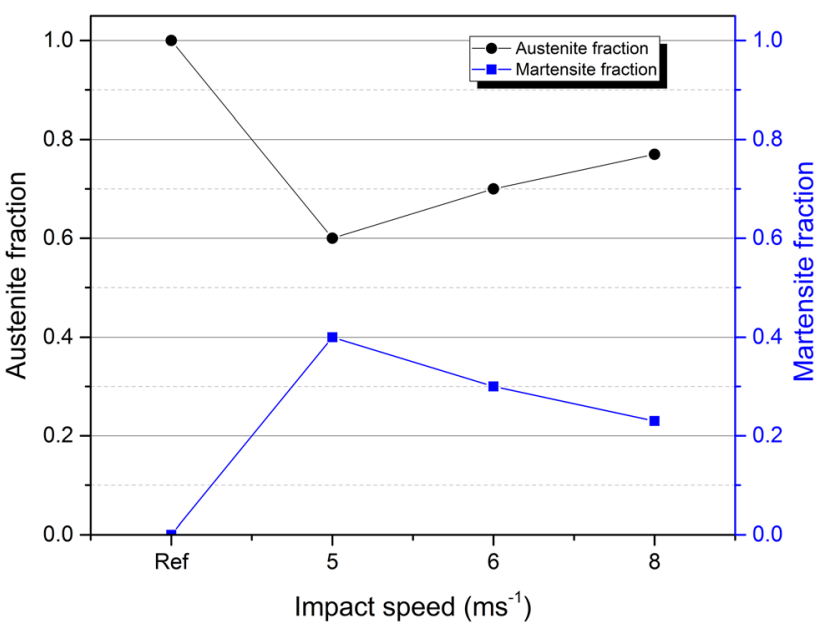

Fig. 12-Fractions of martensite and residual austenite as functions of the impact speed.

obtained martensite fraction decreases as the loading speed increases. ${ }^{[4]}$ The evolutions of the maximum stress (corresponding to the ultimate strain applied to the specimens) and the hardness correlate with martensite fraction as reported in Figure 6. Again, it can be observed that these quantities are greater when the deformation rate is lower, which is consistent with the stronger formation at lower rates of the martensite phase. ${ }^{[46,47]}$ This latter phase is stiffer than the austenite parent phase. The shapes of the specimens before and after compression are shown in Figure 7.

\section{B. Impact Testing}

Figure 8 shows the stress-strain curves during impacts with falling weight at different speeds, while a photograph of the specimens before and after the impacts is shown in Figure 9 with three speeds: 5, 6, and $8 \mathrm{~m} \mathrm{~s}^{-1}$. The difference between the three compression curves is probably due to the formation of martensite. The amount of formed martensite is decreased by arguing the effect of the impact speed on the slow down of martensite transformation kinetics (Figure 10). ${ }^{[45,48]}$

The X-ray diffraction analysis results were conducted by EVA software. That permitted the determination of the compounds corresponding to each peak of diffraction. In fact, the results revealed the existence of two phases; $\gamma$-austenite and $\alpha$ '-martensite. The X-ray diffractograms show that the intensity of the (111) peak corresponding to the $\alpha^{\prime}$ martensite increases and the intensity of the (110) peak corresponding to the austenite decreases. They show too the appearance of a new 


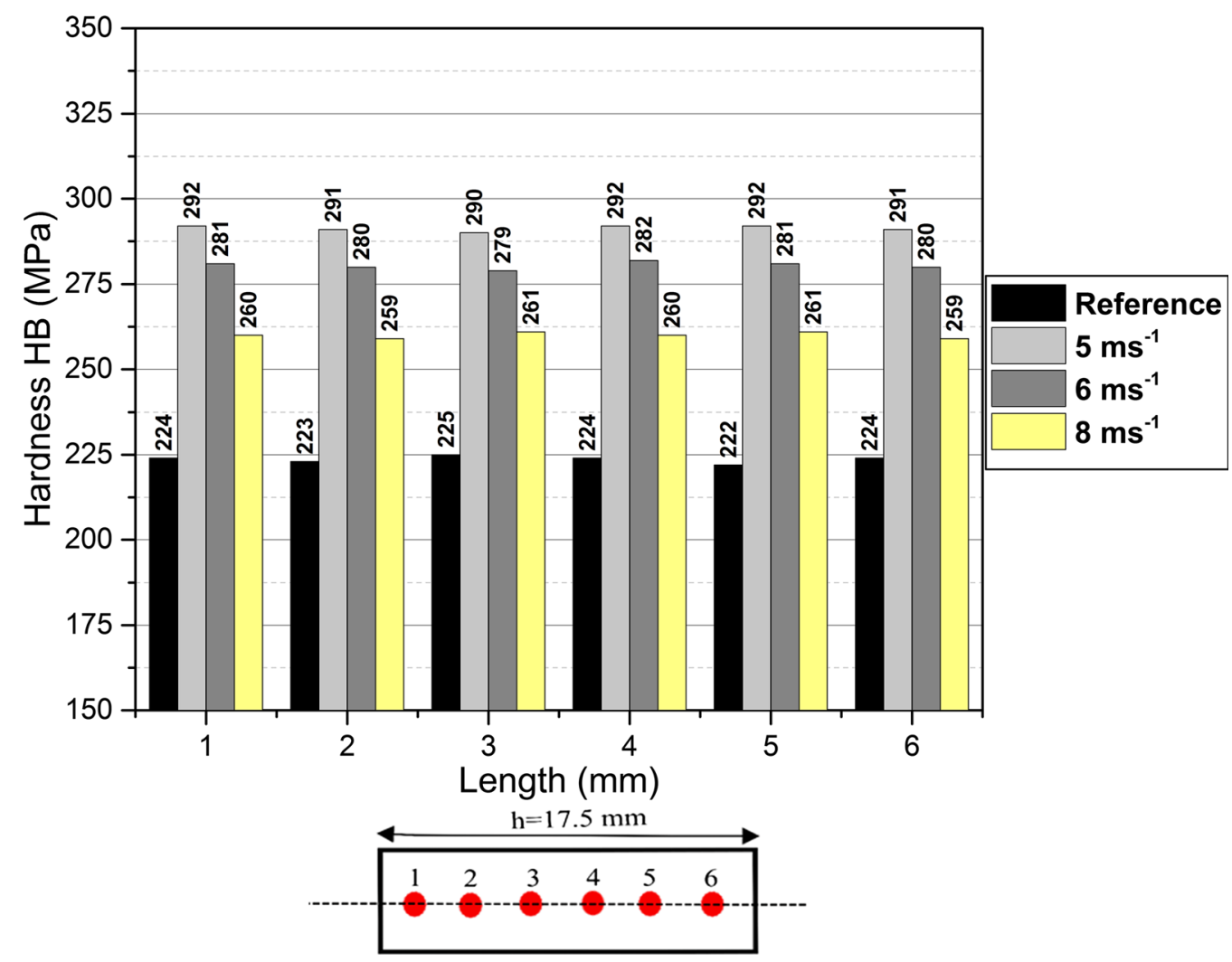

Fig. 13-Distribution of the hardness along the longitudinal direction of the sample for the three tested impact speeds.

peaks such as $\alpha\left(\begin{array}{lll}2 & 2 & 0\end{array}\right), \alpha(311)$ and $\alpha\left(\begin{array}{lll}2 & 2 & 2\end{array}\right)$, and the disappearance of the others like $\gamma\left(\begin{array}{lll}2 & 1 & 1\end{array}\right) .{ }^{[49,50}$

Figure 11 gives an illustration of the microstructural observations made with the Scanning Electron Microscope (SEM) on the deformed specimens. The structure of the $\alpha$-martensite phase can be clearly distinguished on the three micrographs corresponding to the three rates, respectively. The martensite is formed in each case with a structure of long laths. ${ }^{[51,52]}$

Figure 12 gives the fractions of the martensite and the residual austenite phases obtained for each tested rate, i.e., 5,6 , and $8 \mathrm{~m} \mathrm{~s}^{-1}$ in terms of impact speeds (or 294, 352 , and $470 \mathrm{~s}^{-1}$ in terms of strain rates). The amount of formed martensite is well correlated to the speed of the impact, with a greater amount of this phase being produced at lower speed. ${ }^{[53]}$

Figure 13 shows the measured macro-hardness (Brinell) for the various speeds and at different locations along the slug. For a given impact speed, the hardness is quite uniform along the sample. The hardness is the highest for the smallest impact speed, pointing to the larger amount of martensite under these circumstances. Figure 14 shows the measured macro-hardness is correlated with martensite fraction.

Micro-hardness was also investigated with respect to the deformation rate. Figure 15 provides the micro-hardness of both the austenite and the martensite phases. It is noted that the micro-hardness of the martensite phase decreases when the speed is increased, whereas the micro-hardness of the austenite phase follows the opposite.
The hysteresis loops (resulting from an applied magnetic field) of the deformed specimens are presented in Figure 16 for the different impact speeds. The reference specimen, which is undeformed, is nonmagnetic. The values of the coercive magnetic field retrieved from the loops associated with the various impacted specimens are reported in Figure 17. The level of this field is reduced when the deformation rate is high, indicating again that less amount of martensite is formed for higher speeds of impact. ${ }^{[54]}$

To calculate the martensite volume fraction obtained in the magnetic characterization, the following equation was used as suggested by Shimozono et al. ${ }^{[55]}$ :

$$
V_{\alpha}=\left(4 \cdot \pi \cdot M_{\mathrm{S}}^{\prime}\right) \cdot 100 / 10^{4} M_{\mathrm{S}}
$$

where: $M^{\prime}{ }_{\mathrm{S}}$ is the magnetic saturation of the tested sample in the VSM. $M_{\mathrm{S}}$ is the magnetic saturation of the sample considering its total transformation to martensite. $M_{\mathrm{S}}$ was calculated using the equation obtained from Slater Pauling curve. ${ }^{[55]}$

$$
M_{\mathrm{s}}=\{2.2 \cdot(1-x-y)+0.6 x\} \cdot 1.003
$$

where $x$ and $y$ are the molar fractions for $\mathrm{Ni}$ and $\mathrm{Cr}$, respectively.

The evolutions of the saturation and remnant (residual) magnetizations $\left(M_{\mathrm{s}}\right.$ et $\left.M_{\mathrm{r}}\right)$ for the tested specimens are plotted in Figure 18 with respect to the impact speed. The magnetic induction at saturation drops when the deformation rate is increased due again to the martensite formation in lesser proportions. ${ }^{[56,57]}$ 


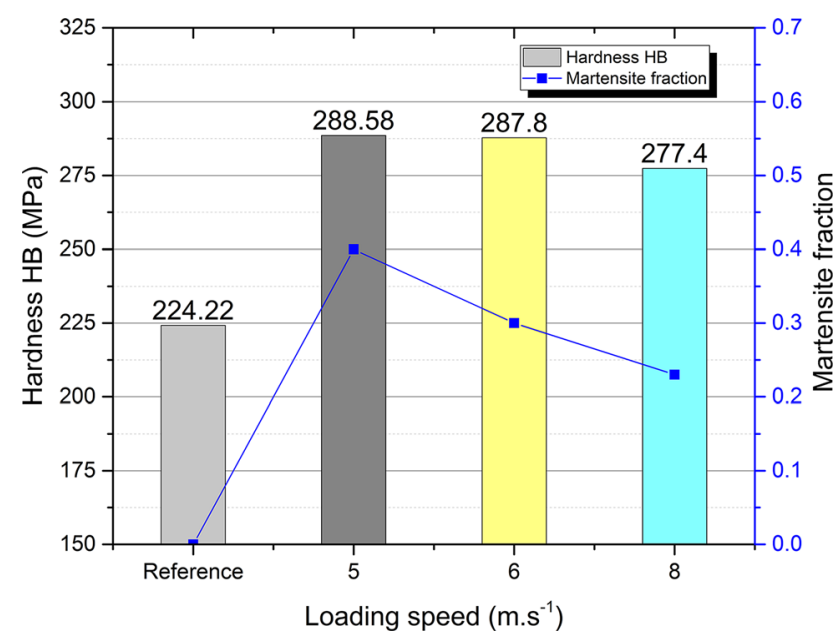

Fig. 14-Hardness of the sample for the three tested impact speeds, correlated with martensite fraction.

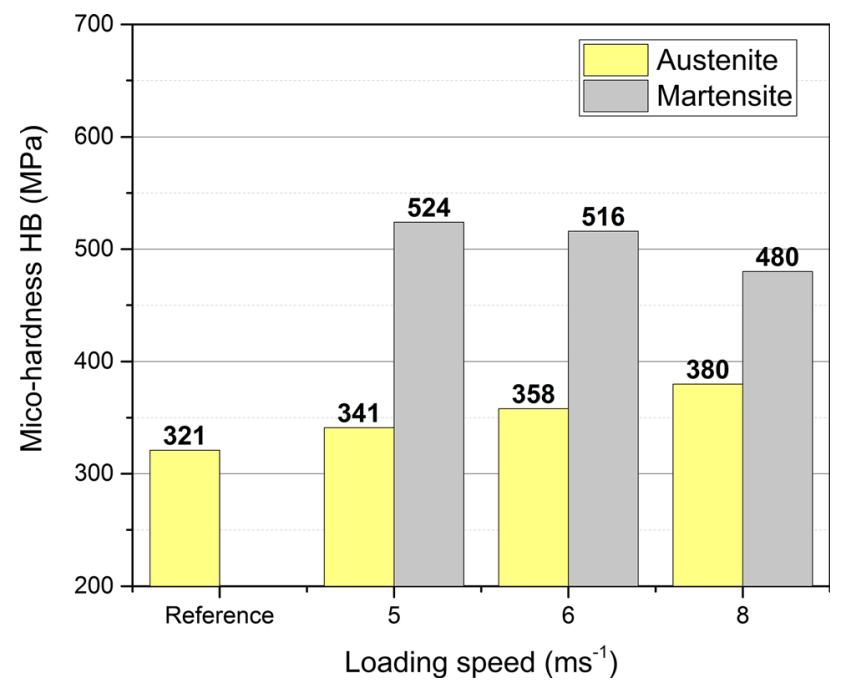

Fig. 15-Micro-hardness of martensite and austenite phases measured for the different impact speeds.

Figure 19 shows the calculated magnetic susceptibility correlate with martensite fraction, i.e., a dimensionless proportionality factor measuring the degree of the material magnetization in the applied magnetic field, as well as the magnetic permeability, which is a close related parameter expressing the ability of the material to support the formation of a magnetic field inside itself. The values of both magnetic parameters drop when the deformation rate is higher. ${ }^{[58,59]}$ As was the case with all previous analyses done with other types of experimental techniques, the amount of formed martensite is maximal for the lowest tested deformation rate.
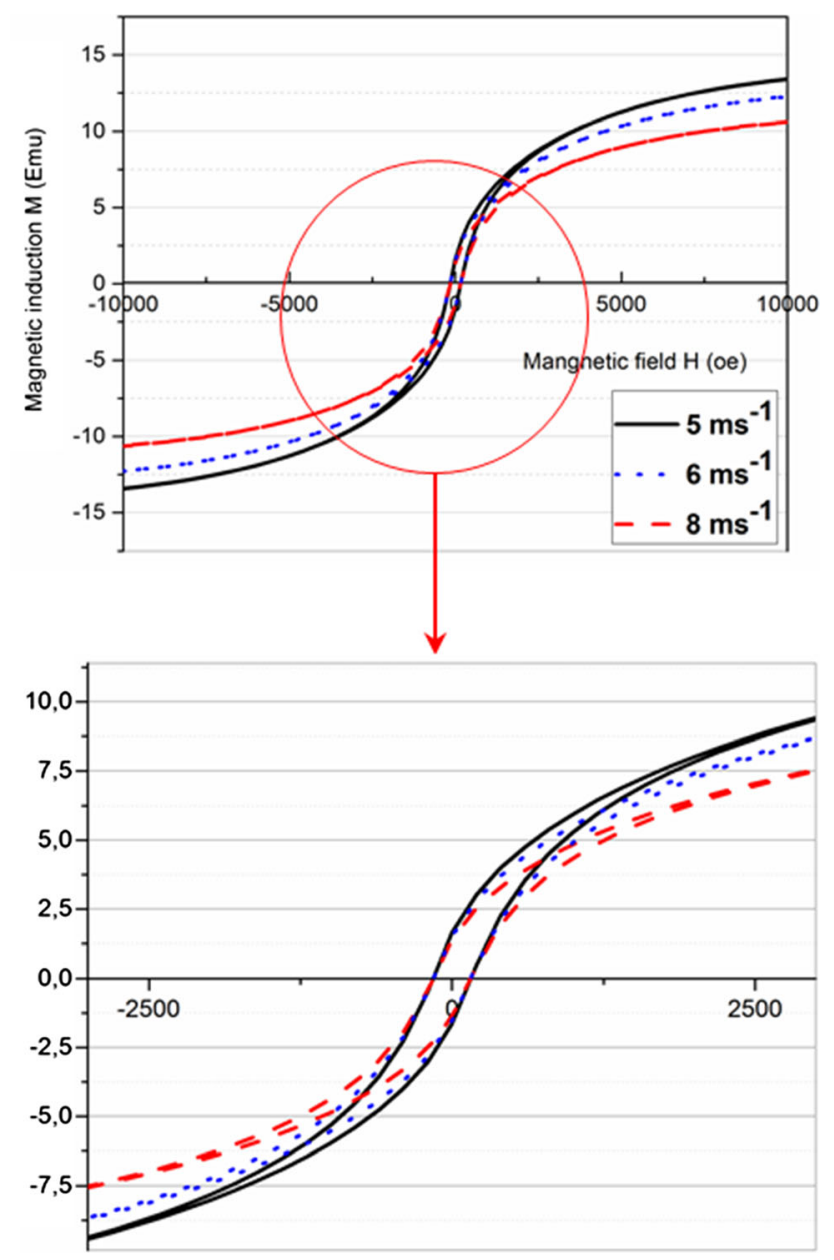

Fig. 16-Analysis by the VSM technique (vibration simple magnetic) of the dynamically deformed specimens.

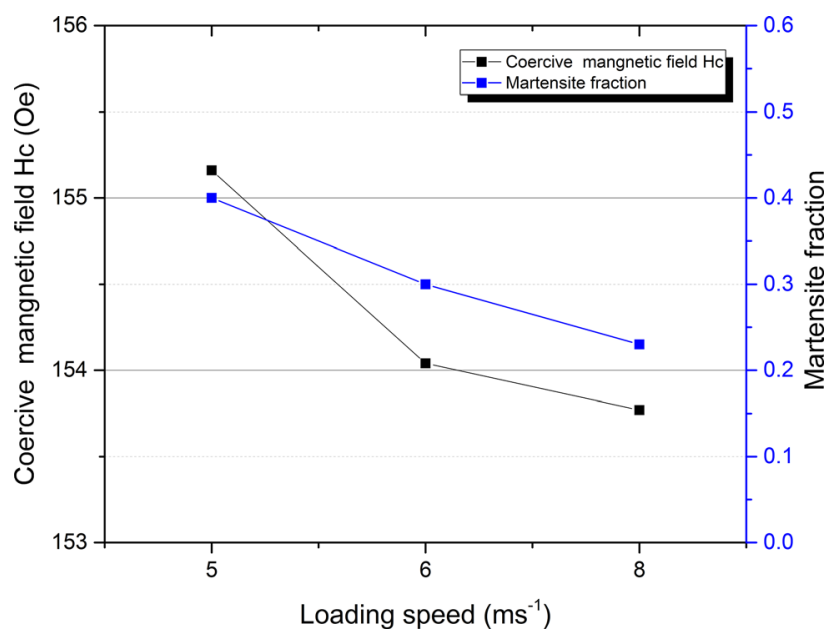

Fig. 17-Evolution of the coercive magnetic field $H_{\mathrm{c}}$, correlated with martensite fraction. 


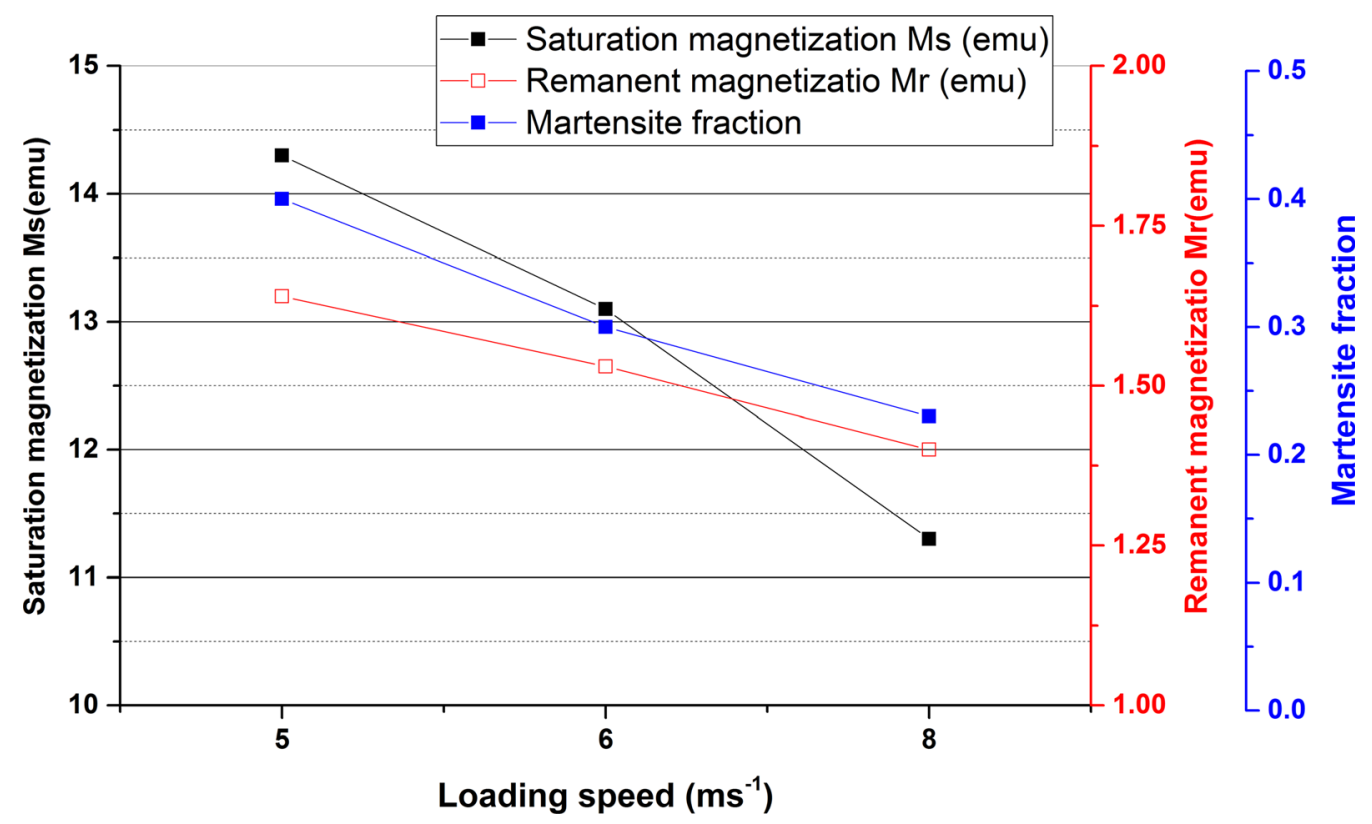

Fig. 18-Magnetic induction at saturation $\left(M_{\mathrm{s}}\right)$ and remanent magnetic induction $\left(M_{\mathrm{r}}\right)$ values for the tested deformation rates, correlated with martensite fraction.

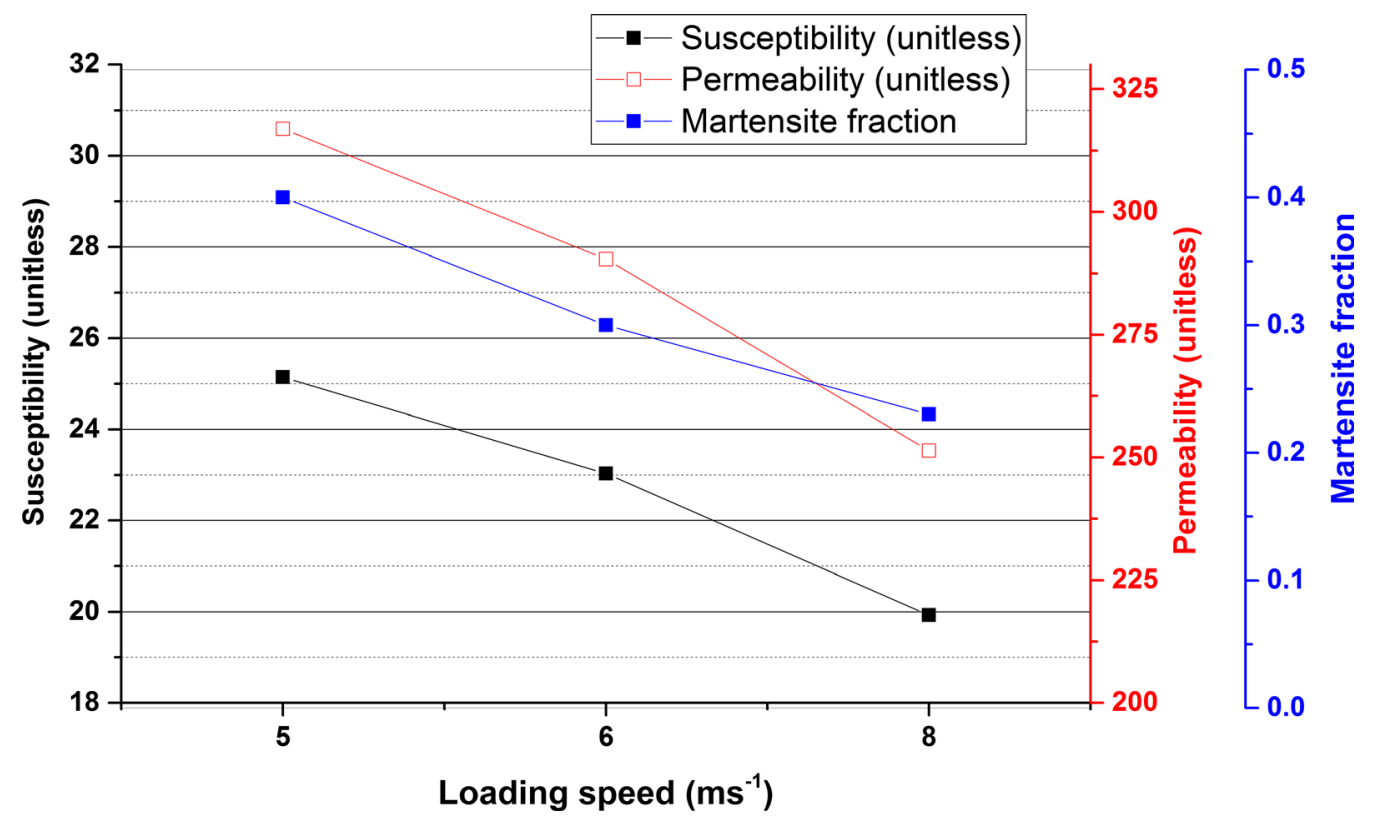

Fig. 19-Evolutions of the magnetic susceptibility and permeability for the three tested deformation rates correlated with martensite fraction.

\section{CONCLUSION}

In this study, the TRIP mechanism occurrence in the unstable stainless steel AISI 304 has been experimentally investigated under quasi-static and impact testing conditions. Formation of martensite has been demonstrated through multiple measurements and observation techniques, while the effects of the loading conditions, mainly the deformation rate, have been established. Macro- and micro-hardness measurements, as well as microscope views, have confirmed that the TRIP mechanism is present in the selected material. Impact tests with a falling weight have been also performed at different speeds in order to assess the influence of the deformation rate on the proportion of martensite that is consequently formed. SEM and XRD analyses indicate that the martensite is formed with a structure of long laths. The magnetic characterization of the specimens with the VSM technique has confirmed the latter analyses at the scale of the entire sample and has permitted to quantify the martensite phase thanks to its 
magnetic properties. As for the influence of the impact speeds, it has been found that the amount of martensite that is formed is inversely proportional to the deformation rate. This result is also corroborated by the hardness measurements: the formation of the stiffer martensite phase compared to the austenite phase leads to the increase of the macro- and micro-hardness values. As lesser proportions of martensite are formed at high deformation rates, the hardness is weaker for elevated impact speeds.

As perspectives for this work, the authors propose to develop a numerical model accounting for the two-phase (austenite and martensite) and being capable of reproducing the martensitic transformation under dynamic loading. Formulated in the finite element framework, the model should be confronted with the present experimental findings. At a later stage, the model may be used in simulations to optimize the energy absorption capacity of AISI 304 steel-based structures. On the experimental level, improvements can be made in the characterization by conducting biaxial and triaxial dynamic loadings in order to assess the effect of the stress triaxiality on the martensitic transformation.

\section{ACKNOWLEDGMENTS}

Authors are grateful to Prof. A. Abdul-Latif, Paris 8 University for hosting our $\mathrm{PhD}$ student and having allowed the realization of a part of the experimental tests.

\section{REFERENCES}

1. W. Mitter: Materialkundlich-Technische Reihe, Berlin-Stuttgart, 1987.

2. J. Galán, L. Samek, P. Verleysen, K. Verbeken, and Y. Houbaert: Rev. Metal. Madrid, 2012, vol. 48, pp. 118-31.

3. Q. Liu, Q. Zhou, J. Venezuela, M. Zhang, J. Wang, and A. Atrens: Corros. Rev., 2016, vol. 34 (3), pp. 127-52.

4. V.F. Zackay, E.R. Parker, D. Fahr, and R. Busch: ASM Trans. $Q ., 1967$, vol. 60 , pp. $252-59$.

5. P. Hausild, V. Davydov, J. Drahokoupil, M. Landa, and P. Pilvin: Mater. Des., 2010, vol. 31, pp. 1821-27.

6. H. Fathi, E. Emadoddin, and H.R. Mohammadian Semnani: $J$. Mater. Res., 2016, vol. 31 (14), pp. 2136-46.

7. G. Colette: INPL, PhD Dissertation, 1978.

8. E. Gautier, J.S. Zhang, and X.M. Zhang: J. Phys. IV, 1995, vol. 5 , pp. 41-50.

9. N.C. Goel, S. Sangal, and K. Tangri: Metall. Trans. A, 1985, vol. 16, pp. 2013-21.

10. S. Sangal, N.C. Goel, and K. Tangri: Metall. Trans. A, 1985, vol. 16, pp. 2023-29.

11. A.K. Sachedv: Acta Metall., 1983, vol. 31, pp. 2037-42.

12. P. Jacques, Q. Furnémont, A. Mertens, and F. Delnnay: Philos. Mag. A, 2001, vol. 81, pp. 1789-1812.

13. H.K.D.H. Bhadeshia: ISIJ Int., 2002, vol. 42, pp. 1059-60.

14. J.R. Patel and M. Cohen: Acta Metall., 1953, vol. 1, pp. 531-38.

15. G.B. Olson and M. Cohen: J. Less-Common Met., 1972, vol. 28 , pp. $107-18$.

16. G.B. Olson and M. Cohen: Metall. Trans. A, 1992, vol. 13, pp. 1907-14.

17. I. Tamura and C.M. Wyman: ASM Int., 1992, pp. 227-42.

18. R.G. Stringfellow, D.M. Parks, and G.B. Olson: Acta Metall. Mater., 1992, vol. 40, pp. 1703-16.
19. G.B. Olson: Processing and Structures, ASM, Ohio, pp 391-424, 1986.

20. P.M. Kelly: JIM, 1992, vol. 33, pp. 235-42.

21. G.B. Olson and M. Azrin: Metall. Trans. A, 1978, vol. 9, pp. 713-21.

22. J. Liu, C. Chen, Q. Feng, X. Fang, H. Wang, F. Liu, and J. Lu: Mater. Sci. Eng., A, 2017, vol. 703, pp. 236-43.

23. F. Marketz and F.D. Fischer: Metall. Mater. Trans. A, 1995 , vol. 26 , pp. 267-78.

24. F.D. Fischer, G. Reisner, E. Werner, K. Tanaka, G. Cailletaud, and T. Antretter: Int. J. Plast., 2000, vol. 16, pp. 723-48.

25. C.L. Magee and H.W. Paxton: Trans. Metall. Soc. AIME, 1968, vol. 242 , pp. 1741-56.

26. C.L. Magee and H.W. Paxton: Carnegie Institute of Technology, 1966.

27. E. Scheil: $Z A A C, 1932$, vol. 207, pp. 21-40.

28. G.W. Greenwood and R.H. Johnson: Proc. R. Soc. Lond. A Math., 1965, vol. 283 (1349), pp. 403-22.

29. P. Jacques, Q. Furnémont, T. Pardoen, and F. Delannay: Acta Mater., 2001, vol. 49, pp. 139-52.

30. M. Erdogan and R. Priestner: Mater. Sci. Technol. Lond., 2002, vol. 18 , pp. 369-76

31. J.C. Videau, G. Cailletaud, and A. Pineau: J. Phys. IV, 1996, vol. 6, pp. $465-74$

32. F. Azzouz, G. Cailletaud, T. Antretter, F.D. Fischer, and K. Tanaka: Proceedings Plasticity, Vancouver, 2000, pp 175-77.

33. J. Talonen, H. Hänninen, P. Nenonen, and G. Pape: Metall. Mater. Trans. A, 2005, vol. 36, pp. 421-32.

34. J. Talonen and H. Hänninen: Acta Mater., 2007, vol. 55 (18), pp. $6108-18$

35. A.A. Lebedev and V.V. Kosarchuk: Int. J. Plast., 2000, vol. 16, pp. 749-67.

36. M.P. Miller and D.L. McDowell: J. Eng. Mater.-T ASME, 1996, vol. 118 , pp. $28-36$

37. T. Iwamoto, T. Tsuta, and Y. Tomita: Int. J. Mech. Sci., 1996, vol. 40 , pp. $173-82$.

38. L. Krüger, S. Wolf, U. Martin, P. Scheller, A. Jahn, and A. Weiss: in Dymat. EDP Sciences, Brüssel, pp 1069-74, 2009.

39. L. Krüger, S. Wolf, U. Martin, P. Scheller, A. Jahn, A. Weiss, and P.R. Scheller: Steel Res. Int., 2011, vol. 82, pp. 1087-93.

40. S.W. Yoo, C.S. Lee, W.S. Park, M.H. Kim, and J.M. Lee: Comput. Mater. Sci., 2011, vol. 50, pp. 2014-27.

41. M. Isakov, S. Hiermaier, and V. kuokkala: Metall. Mater. Trans. $A$, 2015, vol. 46A, pp. 2352-55.

42. Y.F. Shen, X.X. Li, X. Sun, Y.D. Wang, and L. Zuo: Mater. Sci. Eng., A, 2012, vol. 552, pp. 514-22.

43. H. Wang, Y. Jeong, B. Clausen, Y. Liu, R.J. McCabe, F. Barlat, and C.N. Tome: Mater. Sci. Eng. A, 2016, vols. 19-20 (649), pp. 174-83.

44. J.A. Lichtenfeld, M.C. Mataya, and C.J. Van Tyne: Metall. Mater. Trans. A Phys. Metall. Mater. Sci., 2006, vol. 37, pp. 147-62.

45. H. Hamasaki, T. Ohno, T. Nakano, and E. Ishimaru: Int. J. Mech. Sci., 2018, vols. 146-147, pp. 536-43.

46. A.L. Roitburd and G.V. Kurdjumov: Mater. Sci. Eng., 1979, vol. 39, pp. 141-67.

47. S.S.M. Tavares, J.M. Pardal, M.J. Gomes, H.F.G. Abreu, and M.R. Silva.: Mat. Char., 2009, vol. 60/8, pp. 907-11.

48. A.A. Tiamiyu, M. Eskandari, M. Nezakat, X. Wang, J.A. Szpunar, and A.G. Odeshi: Mater. Des., 2016, vol. 112, pp. 309-19.

49. L.E. Murr, K.P. Staudhammer, and S.S. Hecker: Metall. Trans. A, 1982, vol. 13A, pp. 627-35.

50. A.K. De, D.C. Murdock, M.C. Mataya, J.G. Speer, and D.K. Matlock: Scr. Mater, 2004, vol. 50, pp. 1445-49.

51. A. Younes, N. Dilmi, M. Khorchef, A. Bouamer, N.E. Bacha, and M. Zergoug: Appl. Surf. Sci., 2018, vol. 446, pp. 258-65.

52. H. Huang, J. Ding, and P.G. McCormick: Mat. Sci. Eng., 1996, vol. A $216 / 1-2$, pp. $178-84$.

53. V. Tsakiris and D.V. Edmonds: Mat. Sci. Eng., 1999, vol. A 273-275, pp. 430-36.

54. T. Antretter, F.D. Fischer, K. Tanaka, and G. Cailletaud: Steel Res, 2002, vol. 73, pp. 225-35.

55. K. Shibata, T. Shimozono, Y. Kohno, and H. Otsuka: Mater. Trans. JIM, 2000, vol. 41, pp. 893-90. 
56. S.S.M. Tavares, D. Fruchart, and S. Miraglia: J. Alloys Compd., 2000, vol. 307, pp. 311-17.

57. L. Zuo, Y. Zhang, and X. Zhao: Front. Phys. China, 2006, vol. 1, pp. 85-91.

58. T. Kira, K. Murata, S. Inoue, K. Koterazawa, S.J. Jeong, G.S. Yang K. Inoue: Mater. Trans., 2004, vol. 45, pp. 1895-902.
59. F. Lischka: J. Achiev: Mater. Manuf. Eng., 2015, vol. 71, pp. 34-38.

Publisher's Note Springer Nature remains neutral with regard to jurisdictional claims in published maps and institutional affiliations. 